Technical Note

\title{
Development of permeable reactive biobarrier for the removal of PAHs by Trichoderma longibrachiatum
}

\author{
M. Cobas ${ }^{\text {a }}$, L. Ferreira ${ }^{\text {a }}$, T. Tavares ${ }^{\text {b }}$, M.A Sanromán ${ }^{\text {a }}$, M. Pazos ${ }^{\text {a,* }}$ \\ ${ }^{a}$ Department of Chemical Engineering, University of Vigo, Vigo 36310, Spain \\ ${ }^{\mathrm{b}}$ Department of Biological Engineering, University of Minho, Braga 4710-057, Portugal
}

\section{H I G H L I G H T S}

- Innovative permeable reactive barrier using fungus biofilm was developed.

- Trichoderma longibrachiatum over nylon sponge was selected as the bioreactive medium.

- The ability for PAHs removal of the developed bioreactive medium was demonstrated.

\section{A R T I C L E I N F O}

\section{Article history:}

Received 23 August 2012

Received in revised form 9 January 2013

Accepted 10 January 2013

Available online 10 February 2013

\section{Keywords:}

Biobarriers

Bioreactive material

Nylon sponge

PAHs

Permeable reactive

Trichoderma longibrachiatum

\begin{abstract}
A B S T R A C T
In this work, the formation of permeable reactive biobarriers (PRBBs) using Trichoderma longibrachiatum over nylon sponge as bioreactive medium for removal of polycyclic aromatic hydrocarbons (PAHs) was studied. Colony formation was pretested without PAH presence by inoculation of fungus into nylon sponge. The fungus formed a large quantity of strongly adhesive biofilm among nylon sponge. Afterwards, the ability of the developed bioreactive medium was tested to remediate phenanthrene in aqueous medium and in soil. In aqueous medium, a $90 \%$ of phenanthrene concentration reduction was observed after $14 \mathrm{~d}$. However, the pollutant removal in soil requires previous fungus colonization and the attained level was around $70 \%$ after $28 \mathrm{~d}$. Subsequently, the formed bioreactive material was used in a glass column reactor to evaluate its application as PRBBs. Mixtures of phenanthrene, benzo[a]anthracene and pyrene at several concentrations, from 100 to $400 \mu \mathrm{M}$, were treated. In all cases, the performance of the PRBB was satisfactory and total PAH removals were achieved. These results suggest that PRBBs of $T$. longibrachiatum supported on nylon sponge can be an effective method for the treatment of PAHs.
\end{abstract}

(c) 2013 Elsevier Ltd. All rights reserved.

\section{Introduction}

Water is a limited natural resource that may be considered as one of the most important components of the environment. There are several pollution sources of water and groundwater as a result of anthropogenic activities including industrial spills, septic tanks, agricultural areas, underground storage tanks, wastewater treatment works, and unauthorized dump sites (Manoli and Samara, 1999; Tredoux et al., 2004). Because of this, the polluted water becomes harmful to vegetation, animals and humans. At the present time, there are a wide variety inorganic, organic and synthetic compounds that are discharged to the environment and become water contaminants. Amongst them, the presence of emerged organic pollutant such as polycyclic aromatic hydrocarbons (PAHs)

\footnotetext{
* Corresponding author. Tel.: +34 986818723.

E-mail address: mcurras@uvigo.es (M. Pazos).
}

is taking the attention of scientific community (Zein et al., 2006; Gibert et al., 2007).

PAHs are spread to the environment mainly as a result of anthropogenic activities and in spite of their low solubility they can be present in surface water and groundwater (Manoli and Samara, 1999). PAHs are organic compounds that consist of more than two bonded aromatic rings and are formed in the incomplete decomposition of organic molecules. They are important environmental contaminants and clear mutagenic/carcinogenic compounds, which are included in a list of pollutants by United States Environmental Protection Agency and EU Water Framework Directives (2000/60/EC) (EU, 2000; Haritash and Kaushik, 2009). In this study several PAHs, such as phenanthrene (PHE), benzo[a]anthracene (BAA) and pyrene (PYR) were selected because they are representative PAHs for monitoring and control PAHs emissions of in the environment (Inengite et al., 2012).

Currently, permeable reactive barriers technology is considered an innovative, cost-effective and environmentally sound method 
for the in situ groundwater remediation (Warner, 2011). In this technology, a reactive medium is placed in the subsurface across the flow a plume of contaminated groundwater, which must move under its natural gradient, thereby creating a passive treatment system (Thiruvenkatachari et al., 2008).

The permeable reactive barriers technology can also benefit from other types of remediation, such as bioremediation. Several researchers have determined the biodegradative capacity of PAHs of both bacteria and fungi in contaminated land and waters (Haritash and Kaushik, 2009; Moscoso et al., 2012). PAH-degrading microorganisms can act by anaerobic or aerobic metabolism. The basis of aerobic metabolisms is the oxidation of the aromatic ring, followed by the systematic breakdown of the compound to PAH metabolites and/or carbon dioxide. On the other hand the anaerobic metabolism of PAHs occurs via the hydrogenation of the aromatic ring (Bamforth and Singleton, 2005).

Accordingly, permeable reactive barriers can be coupled with bioremediation forming the named permeable reactive biobarriers technology (PRBBs). In this technology, the microorganisms, retained on the soil surface or on a porous support, are used as reactive medium to degrade or stabilize the contaminants in the groundwater (Choi et al., 2007; Seo and Bishop, 2008; Tiehm et al., 2008). In addition to the microbial activity, biofilm formation plays important role in the performance of the PRBB (Harding et al., 2009). In spite that the biofilm ability is mainly related to bacteria and yeast, researchers have reported that some filamentous fungi as Aspergillus and Trichoderma are able to grow on hard surfaces forming biofilm (Te Biesebeke et al., 2002; Villena and GutierrezCorrea, 2003b).

The genera Trichoderma, isolated from oil polluted sites, have been reported as benzoapyrene-degrading microorganisms, converting it into intermediate metabolites, such as benzo(a)pyrene trans, 4,5-dihydrodiol, benzo(a)pyrene trans 8,9 dihydrodiol, benzo(a)pyrene trans, 9,10 dihydrodiol, and benzo(a)pyrene 1,6 quinone (Mueller et al., 1998). In addition our previous studies have determined the enormous potential of the isolated fungus Trichoderma longibrachiatum in the degradation of high-molecular weight PAHs such as BAA (Rosales et al., 2012b).

Several materials can be used as support to biofilm formation; however the use of low cost supports such as agro-industrial wastes (orange peel and potato peel), solid organic materials (mulch and peat moss) or inorganic materials (nylon sponge) is attracting the interest of scientific community (Yerushalmi et al., 1999; Rosales et al., 2012a). Among them, the biofilm formation over nylon sponge seems to be adequate low cost support to form PRBBs. The immobilization in nylon sponge offers a physical retention, without reaction with the microorganisms or pollutants and providing a homogeneous solid support.

Based on the above, the aim of this work is to evaluate the formation of bioreactive material for PRBBs using T. longibrachiatum over nylon sponge. Afterwards, the developed bioreactive material will be tested to PHE remediation in aqueous medium and soil. Finally, the performance PRBB using the developed material will be examined in column reactor to treat a solution of PAH mixture.

\section{Materials and methods}

\subsection{Microorganism}

T. longibrachiatum was isolated from waste containers, polluted with PAHs and heavy metals (Rosales et al., 2012b). The genetic identification of the strain was done using PCR AmpliTaq DNA polymerase and was compared with sequences in public databases of GeneBank (Rosales et al., 2012b). The isolated strain was maintained in Potato Dextrose Agar (PDA) plates at $4{ }^{\circ} \mathrm{C}$.

\subsection{Growth medium (GM)}

The GM was composed of $\left(\mathrm{g} \mathrm{L}^{-1}\right) \mathrm{Na}_{2} \mathrm{HPO}_{4} \cdot 2 \mathrm{H}_{2} \mathrm{O} 8.5, \mathrm{KH}_{2} \mathrm{PO}_{4}$ 3.0, $\mathrm{NaCl} 0.5, \mathrm{NH}_{4} \mathrm{Cl} 1.0, \mathrm{MgSO}_{4} \cdot 7 \mathrm{H}_{2} \mathrm{O} 0.5, \mathrm{CaCl}_{2}$ 0.0147, mycological peptone 1 , glucose 10 . The $\mathrm{pH}$ was initially adjusted to five with $\mathrm{HCl}$ and was autoclaved at $121^{\circ} \mathrm{C}$ for $20 \mathrm{~min}$. After that trace elements were added by $0.22 \mu \mathrm{m}$ filtration $\mathrm{MgSO}_{4} 0.24 \mathrm{~g} \mathrm{~L}^{-1}, \mathrm{CaCl}_{2}$ $0.555 \mu \mathrm{g} \mathrm{L}^{-1}$ and micronutrients solution (in $\mathrm{g} \mathrm{L}^{-1}$ ) was composed of $\mathrm{CuSO}_{4} 4 \times 10^{-4}$, KI $1 \times 10^{-3}, \mathrm{MnSO}_{4} \cdot \mathrm{H}_{2} \mathrm{O} 4 \times 10^{-3}, \mathrm{ZnSO}_{4} \cdot 7 \mathrm{H}_{2} \mathrm{O}$ $4 \times 10^{-3}, \quad \mathrm{H}_{3} \mathrm{BO}_{3} 5 \times 10^{-3}, \quad \mathrm{H}_{2} \mathrm{MoO}_{4} \cdot 2 \mathrm{H}_{2} \mathrm{O} \quad 1.6 \times 10^{-3}$ and $\mathrm{FeCl}_{3} \cdot 6 \mathrm{H}_{2} \mathrm{O} 2 \times 10^{-3}$.

\subsection{Column assays medium (RM)}

The removal medium (RM) used in the column assays was composed of aqueous solution of PHE, BAA and PYR in Tween $801 \%$, acetone $2 \%$ and minimal medium of $\left(\mathrm{g} \mathrm{L}^{-1}\right) \mathrm{Na}_{2} \mathrm{HPO}_{4} \cdot 2 \mathrm{H}_{2} \mathrm{O} 8.5$, $\mathrm{KH}_{2} \mathrm{PO}_{4} 3.0, \mathrm{NaCl} 0.5, \mathrm{NH}_{4} \mathrm{Cl} 1.0, \mathrm{MgSO}_{4} \cdot 7 \mathrm{H}_{2} \mathrm{O} \quad 0.5, \mathrm{CaCl}_{2} 0.0147$. The $\mathrm{pH}$ was initially adjusted to five with $\mathrm{HCl}$ and was autoclaved at $121{ }^{\circ} \mathrm{C}$ for $20 \mathrm{~min}$. After that trace elements were added by $0.22 \mu \mathrm{m}$ filtration $\mathrm{MgSO}_{4} 0.24 \mathrm{~g} \mathrm{~L}^{-1}, \mathrm{CaCl}_{2} 0.555 \mu \mathrm{g} \mathrm{L}^{-1}$ and micronutrients solution was composed of $\left(\mathrm{g} \mathrm{L}^{-1}\right) \mathrm{CuSO}_{4} 4 \times 10^{-4}$, KI $1 \times 10^{-3}, \quad \mathrm{MnSO}_{4} \cdot \mathrm{H}_{2} \mathrm{O} 4 \times 10^{-3}, \quad \mathrm{ZnSO}_{4} \cdot 7 \mathrm{H}_{2} \mathrm{O} 4 \times 10^{-3}, \mathrm{H}_{3} \mathrm{BO}_{3}$ $5 \times 10^{-3}, \mathrm{H}_{2} \mathrm{MoO}_{4} \cdot 2 \mathrm{H}_{2} \mathrm{O} 1.6 \times 10^{-3}$ and $\mathrm{FeCl}_{3} \cdot 6 \mathrm{H}_{2} \mathrm{O} 2 \times 10^{-3}$.

\subsection{Support}

Fibrous nylon sponge was used for the immobilization of fungus (Scotch brite TB, 3M Company, Spain). This supporting matrix allows the exchange of nutrients and/or the flow of the medium through it. The nylon sponge was pretreated according to Moldes et al. (2003) by boiling for $10 \mathrm{~min}$ and washing thoroughly 3 times with distilled water. After that, the supports were dried at room temperature overnight and autoclaved at $121^{\circ} \mathrm{C}$ for $20 \mathrm{~min}$.

\subsection{Soil}

Soil samples were collected from the northwest of Spain (Galicia) (Pazos et al., 2011). Using an Eijkelkamp sampler, the soil samples were taken of the top $30 \mathrm{~cm}$ in different points. Soil mineralogical analysis, $\mathrm{pH}$ and texture are shown in Table 1 . The collected samples were mixed and sieved and the fraction containing particles of sizes $<2 \mathrm{~mm}$ was selected. After that, the soil samples were polluted with PHE (98\% Aldrich) by adding the PAH dissolved in hexane. The polluted soil was placed in a ventilation hood for $9 \mathrm{~d}$ until the hexane completely evaporated. The initial concentration of PHE in the soil was approximately $285 \mathrm{mg} \mathrm{kg}^{-1}$ of dried soil.

\subsection{Experimental set-up}

\subsubsection{Developed of bioreactive material}

To obtain T. longibrachiatum biofilm over fibrous nylon sponge, bioreactive material, submerged aerobic cultures were prepared in $250 \mathrm{~mL}-$ Erlenmeyer flasks with $15 \mathrm{~mL}$ of GM and $1 \mathrm{~g}$ nylon sponge $(0.5 \times 0.5 \mathrm{~cm})$. The flasks were inoculated with 4 -agar portion (diameter, $3 \mathrm{~mm}$ ), extracted from a fungal colony growing on PDA plate. The flasks were incubated for $7 \mathrm{~d}$ at $30^{\circ} \mathrm{C}$ in darkness with dynamic incubation at $50 \mathrm{rpm}$ with a passive aeration permitted by cellulose stoppers.

\subsubsection{Bioreactive material performance to PHE removal in aqueous medium}

Once the biofilm was formed on the support, henceforth bioreactive material, the GM was removed from the Erlenmeyer flasks and changed by $15 \mathrm{~mL}$ of aqueous solution of PHE. The aqueous 
Table 1

Soil mineralogical analysis, $\mathrm{pH}$ and texture.

\begin{tabular}{llll}
\hline Characteristics & & Mineralogical analysis (\%) \\
\hline Origin & Northwest Spain & Kaolinite & 3.6 \\
Type & Loamy sand & Mica & 7.7 \\
$\mathrm{pH}$ & 4.5 & Quartz & 48.9 \\
& Calcite & $\mathrm{ND}$ \\
& Dolomite & 3.4 \\
& Albite & $\mathrm{ND}$ \\
& Chlorite & $<1$ \\
& Illite & $\mathrm{ND}$ \\
& Orthoclase & 18.2 \\
\hline
\end{tabular}

solution was prepared dissolving PHE (98\% Aldrich) at a concentration of $1000 \mu \mathrm{M}$ in aqueous medium using 1\% Tween 80 and $2 \%$ acetone. The flasks containing PHE solution and biofilm over nylon sponge were maintained at darkness in an environmental chamber at $30{ }^{\circ} \mathrm{C}$ and $90 \%$ humidity, to prevent evaporation. The experiments were performed in duplicated for each time $(0,7,14,21$ and $28 \mathrm{~d}$ ). Each experimental set was stopped at desired contact time in order to not disturb the system. Abiotic controls were carried out in parallel in order to evaluate the pollutant volatilization or the pollutant adsorption onto nylon sponge.

\subsubsection{Bioreactive material performance to PHE removal in soil}

For the PAH soil removal assays, $10 \mathrm{~g}$ of PHE polluted soil, prepared according to Section 2.5, were placed in $250 \mathrm{~mL}$-Erlenmeyer flasks and were autoclaved. After that, $6 \mathrm{~mL}$ of GM and the biofilm over nylon sponge ( $7 \mathrm{~d}$ old $)$ were transferred to the flask with the polluted soil. The flasks containing PHE polluted soil and biofilm over nylon sponge were maintained at the same conditions as previous experiments. The experiments were performed in duplicated for each time $(0,7,14,21$ and $28 \mathrm{~d})$. Each experimental set was stopped at desired contact time in order to not disturb the system. Abiotic controls were carried out in parallel in order to evaluate the pollutant volatilization.

\subsubsection{Column reactor assays}

A glass reactor, consisting of a column (diameter $4 \mathrm{~cm}$; height $50 \mathrm{~cm}$; working volume $0.6 \mathrm{~L}$ ) filled with the bioreactive material, was employed to perform the present study. Initially, the biofilm formation was carried out in a $1 \mathrm{~L}-F e r n b a c h$ flask with $100 \mathrm{~mL}$ of GM and 13 discs (3.5 cm diameter and $0.5 \mathrm{~cm}$ thickness) and $27-$ agar portion (diameter, $3 \mathrm{~mm}$ ) extracted from a fungal colony growing on PDA plate. The Fernbach flask was incubated for 1 week at $30^{\circ} \mathrm{C}$ in darkness with dynamic incubation at $50 \mathrm{rpm}$ and a passive aeration permitted by cotton plugs. After the biofilm formation, the discs were fixed in a steel rod with a plastic spacer of $0.3 \mathrm{~cm}$ and this rod was inserted in the glass column reactor. The bioreactor was kept at $30^{\circ} \mathrm{C}$ in a thermostatic chamber and the air

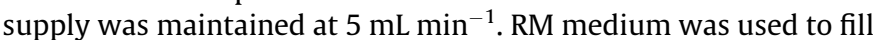
the reactor. Several concentrations were assayed for each PAHs ranged from 100 to $400 \mu \mathrm{M}$ at successive batches and peristaltic pumps were used to simulate the natural horizontal flow through PRBB. PAHs solutions were prepared dissolving the PHE (98\% Aldrich), BAA (99\% Aldrich) and PYR (99\% Aldrich) at a desired concentration in aqueous medium using $1 \%$ Tween 80 and $2 \%$ acetone. Samples were taken periodically in the middle of the column to evaluate PAH removal.

\subsection{Sample treatment and analysis}

\subsubsection{Scanning electron microscopy analyses}

A series of scanning electron microscopy (SEM) images were taken to provide a visual characterization of the fungus grown over the support. The samples were dehydrated, critical point dried, coated with gold and then photographed. Images were collected on a FE-SEM JSM6700 F (JEOL) scanning electron microscope using an accelerating voltage of $10 \mathrm{kV}$ (Electron Microscopy Service, C.A.C.T.I., University of Vigo).

\subsubsection{PAH analysis in aqueous samples}

$\mathrm{PAH}$ concentration in aqueous samples was determined by HPLC (Agilent 1100) equipped with an XDB-C8 reverse-phase column $(150 \times 4.6 \mathrm{~mm}$ id, $5 \mu \mathrm{m})$. Prior to injection, the samples were centrifuged $(10000 \mathrm{rpm}, 5 \mathrm{~min})$ and filtered through a $0.45 \mu \mathrm{m}$ Teflon filter. The PAH concentration was measured following the standard method UNE-EN ISO 17993. The injection volume was set at $5 \mu \mathrm{L}$, and the isocratic eluent (60:40 acetonitrile:water)

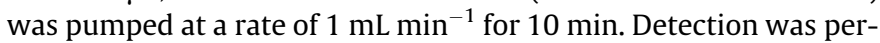
formed with a diode array detector from 100 to $400 \mathrm{~nm}$, and the column temperature was maintained at $20^{\circ} \mathrm{C}$. Duplicated measures were done and the deviation standards were lower than $5 \%$.

\subsubsection{PAH analysis in biofilm}

To determine the PAHs adsorbed by the biofilm a solid-liquid extraction was done. Samples of biofilm were crushed prior solid-liquid extraction to eliminate the interstitial fluid. Then, $10 \mathrm{~mL}$ of methanol were added to crushed biofilm and shacked at $150 \mathrm{rpm}$ for $24 \mathrm{~h}$. The residual PAHs in methanol solution were determined by HPLC.

\subsubsection{PHE analysis in soil samples}

The PHE was extracted from the soil by fast high-pressure extraction in a PSEOne (Pressurized solvent extraction) (EPA Method 3545). Dry samples, after 1 week in $30^{\circ} \mathrm{C}$ oven, were thoroughly mixed with pelletized diatomaceous earth. The resulting free-flowing powder was placed into an extraction vessel in the instrument. The extraction was realized by 4 cycles of 5 min each at $110^{\circ} \mathrm{C}$ and $10 \mathrm{MPa}$, the solvent employed was hexane:acetone $1: 1(\mathrm{v} / \mathrm{v})$. The collected sample was used to determine the PHE concentration by HPLC as it was described in previous section. Duplicated measures were done and the deviation standards were lower than $8 \%$.

\subsection{5. $p H$}

The $\mathrm{pH}$ in liquid samples was measured directly with an IQ Scientific Instruments $\mathrm{pH}$ metre (model Stainless Steel ISFET $\mathrm{pH}$ Probes). The soil pH was measured by adding a distilled $\mathrm{H}_{2} \mathrm{O}$ to the dry sample in a ratio of $2.5 \mathrm{~mL} \mathrm{~g}^{-1}$. After $1 \mathrm{~h}$ of contact time, the $\mathrm{pH}$ was measured with an IQ Scientific Instruments $\mathrm{pH}$ metre (model Stainless Steel ISFET pH Probes).

\section{Results and discussion}

\subsection{Bioreactive material characterization}

One of the most important points to biobarrier formation is to get a proper retention of the microorganism over the selected support. The microorganism selected for this study, T. longibrachiatum, belongs to the filamentous fungi species that are naturally adapted to growth on surfaces. Filamentous fungi require close contact with the substrate due to heterotrophic nutrition, secretion of extracellular enzymes, absorption of nutrients through the cell wall and apical growth of the hyphae (Jones, 1994). Thus, it can be inferred that these fungi have a tendency to the formation of biofilms, which can develop even on synthetic materials.

Nylon sponge had been successfully used for white-rot fungi retention to industrial applications as enzyme production or effluent treatment (Rosales et al., 2002). Accordingly, this support was chosed as a result of its adequate characteristics because it offers 

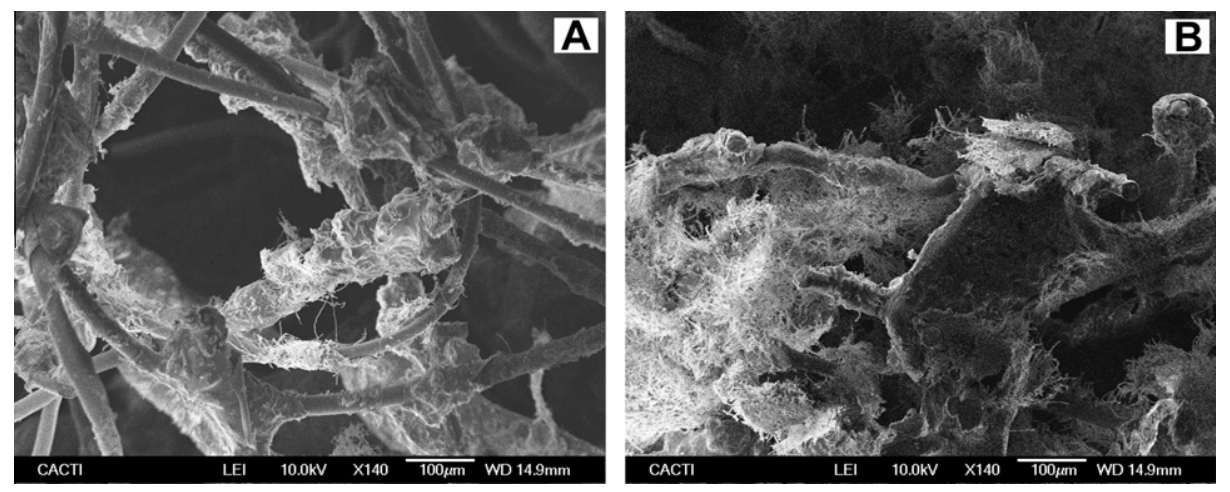

Fig. 1. Scanning electron microscopy microphotographs of $T$. longibrachiatum grown over nylon sponge after 2 (A) and 7 (B) days.

an inert physical retention providing a homogeneous solid support. In addition, it is expected that the nylon porous structure allows a good contact between the polluted flow and the microorganisms.

T. longibrachiatum biofilm developed on nylon sponge was evaluated considering two aspects related to the biobarrier formation: structure and physiological behavior focused on $\mathrm{PAH}$ removal (studied in the next section). The biofilm structure was assessed by using SEM microphotographs. The biofilm formation is a process which can be distinguished in three phases which include the initial cell adhesion, growth and development and maturation (Villena and Gutierrez-Correa, 2003a). The limiting step of the process is the accession of spores to a surface, which is influenced by physical, chemical and environment. In Fig. 1A, the fungal growth among nylon fibres can be appreciated since the first days. An effective adhesion and growth from the spore germination was demonstrated. After $7 \mathrm{~d}$ almost all available nylon fibres surface has been colonized (Fig. 1B). In this figure, it can be clearly appreciated that the biomass density highly increased in comparison to initial days (Fig. 1A). Nevertheless, there are internal channels that guarantee the flow through biofilm. Hence, the biofilm structure examined by SEM analysis clearly shows that the nylon sponge is an adequate support for the T. longibrachiatum growth.

\subsection{Bioreactive material performance to PHE removal}

As it was stated in previous section, once the bioreactive material was formed, it is necessary to evaluate its physiological behavior focused on PAH removal. To overcome this issue, different experimental sets were realized in order to evaluate the bioremoval ability of developed biofilm in aqueous medium and in soil.

\subsubsection{PHE removal in aqueous medium}

Our previous studies (Rosales et al., 2012b) have determined the enormous potential of $T$. longibrachiatum in the degradation of BAA in liquid cultures, however the performance of the T. longibrachiatum biofilm for PAH removal had not reported yet. Therefore, an important step of this study was to demonstrate the ability of T. longibrachiatum biofilm to PAH removal. Initially, the removal of PHE, a molecule composed of three fused benzene and widely used as an indicator for monitoring PAH-contaminated sites (Sack et al., 1997), was assayed. The experiment using fungus biofilm over nylon sponge was monitored for 4 weeks. The system $\mathrm{pH}$ was constantly increased during the experiments from 5 at $0 \mathrm{~d}$ to 6.3 at $28 \mathrm{~d}$ of experiment while there were no observable changes in $\mathrm{pH}$ of the controls. Thus, the changes on $\mathrm{pH}$ were attributed to microbial activity. After 1 week, the removal of PHE in aqueous medium was higher than 60\% (Fig. 2A). Similar results were reported by Raghukumar et al. (2006) who used the marine fungus NIOCC\# 312 immobilized in polyurethane foam for PHE removal/ degradation. The removal increased up to $90 \%$ after second week, reaching the maximum removal around $97 \%$ after $21 \mathrm{~d}$ of treatment. After experiments, the residual PHE retained by the biofilm was lower than $2 \%$ and negligible PHE reduction of concentration was observed in abiotic control. This means that PAH removal was only due to biological action. According to our previous study (Rosales et al., 2012b) the removal of PAHs by T. longibrachiatum can be adjusted to a logistic Eq. (1) in which D is the PAH removal degree (\%) at a specific moment of the culture time $\mathrm{t}(\mathrm{d}), D_{0}$ and $D_{\text {max }}$ are the initial and maximum removal percentage (\%), respectively, and $\mu_{D}$ is the maximum specific degradation rate $\left(\mathrm{d}^{-1}\right)$.

$D=\frac{D_{\max }}{1+e^{\left[\ln \left(\frac{D_{\max }}{D_{0}}-1\right)-\mu_{D} t\right]}}$

Sigma Plot 8.0 software was utilized to adjust the experimental data to model using an iterative procedure, based on the Marquardt-Levenberg algorithm, which seeks the values of the parameters that minimize the sum of the squared differences between the observed and predicted values of the dependent variable.

The logistic model fitted well to data achieving a high determination coefficient, $r^{2}=0.995$. The maximum specific removal rate, $1.13 \mathrm{~d}^{-1}$, was similar to that obtained for the degradation of ben[a]anthracene in free cultures of T. longibrachiatum, $1.6 \mathrm{~d}^{-1}$ (Rosales et al., 2012b). Therefore, it can be stated that working with the fungus biofilm does not significantly reduce the removal efficiency.

\subsubsection{PHE removal in soil}

In this work the treatment of PHE polluted soil with fungus biofilm was studied. Once the bioreactive material was transferred to flask containing PHE polluted soil, the fungus colonization was efficiently performed and after $5 \mathrm{~d}$ and homogenous fungus wrap over the soil was observed. As it is shown in Fig. 2B, for rate was not constant and there was a rise in the last weeks of treatment from $37 \%$ to $63 \%$. The significant increase of PHE removal is possibly related with the time of exposition and adaptation of the fungi to PHE polluted soil. This fact is in agreement with the performance reported by Rivera-Cruz et al. (2002). They found that genera Trichoderma have mechanisms of physiological adaptation in soil, probably of genetic origin, which permit to use PAH carbon in their cellular multiplication. Furthermore, the metabolic activity of fungus for PAHs is widely influence by medium $\mathrm{pH}$ (Haritash and Kaushik, 2009), thus soil pH was monitoring. In comparison with control assays, where $\mathrm{pH}$ was kept around $\mathrm{pH}=4.5$, a continuous increase of soil $\mathrm{pH}$ due to microbial activity was development for 4 weeks of treatment (Fig. 2B). Gaanappriya et al. (2011) stated that the fungus metabolic has its optimum $\mathrm{pH}$ for the growth and xylan-degrading enzyme production between 5.5 and 5.7. 


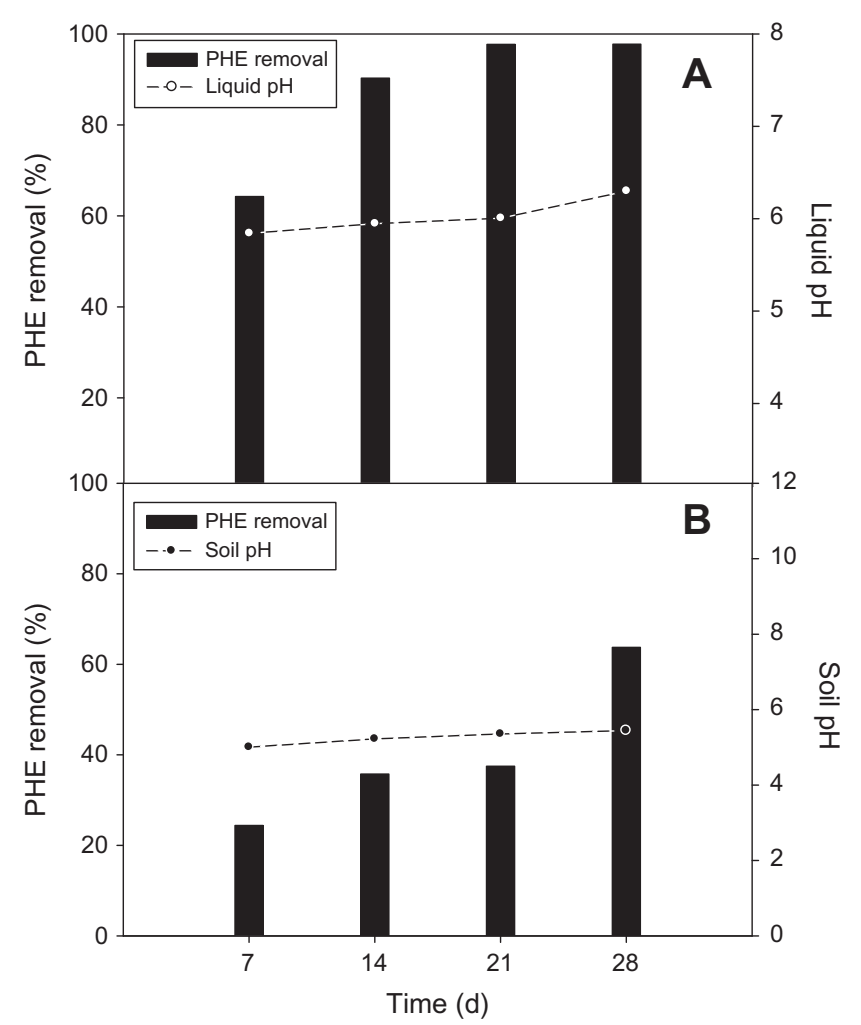

Fig. 2. PHE removal profiles and $\mathrm{pH}$ evolution by using T. longibrachiatum biofilm over nylon sponge. (A): In aqueous medium (initial PHE concentration $1000 \mu \mathrm{M}$ at $\mathrm{pH}$ 5) and (B): in soil (initial PHE concentration $285 \mathrm{mg} \mathrm{kg}^{-1}$ at $\mathrm{pH} 4.5$ ).

And these values coincide with the soil $\mathrm{pH}$ developed in the last week when rate was highest.

\subsection{Biobarrier column reactor assays}

After demonstrating the viability of the developed bioreactive material to PHE removal in several environments (aqueous medium and soil), it was necessary to evaluate its application as PRBB. Therefore column reactor assays using the developed material were carried out. Mixture of three model PAHs, PHE, BAA and PYR were treated in the glass column reactor. In Fig. 3, the evolution of PAH concentrations in the glass column along the time is

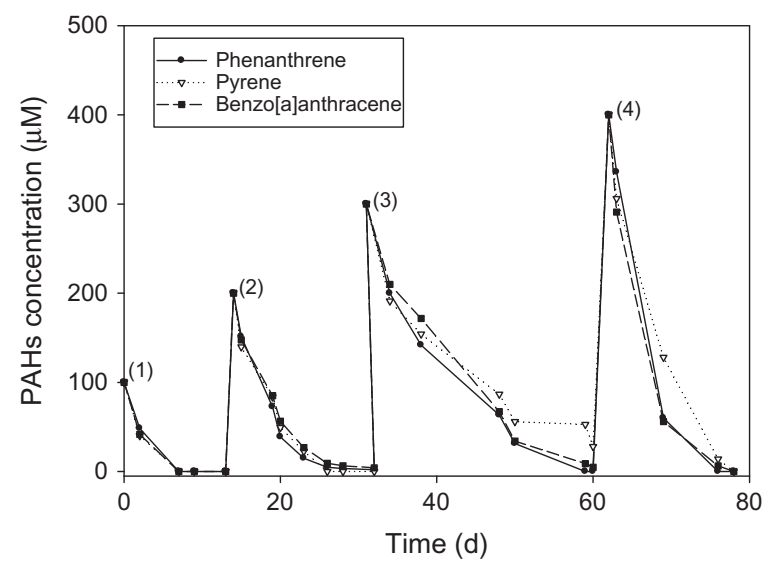

Fig. 3. PAHs removal by T. longibrachiatum biofilm over nylon sponge column batch reactor assays. Initial PAHs concentration: $100 \mu \mathrm{M}$ (1), $200 \mu \mathrm{M}(2), 300 \mu \mathrm{M}$ (3) and $400 \mu \mathrm{M}(4)$. represented. As it is shown, in all tested concentrations a total PAH removal was achieved and the bioremoval rates do not differ significantly for the different studied PAHs. It is postulated that the rapid disappearance of PAHs from aqueous medium is due to a first step of adsorption to the fungal biomass. Many researchers have reported that hydrophobic organic compound have a high affinity for biofilms (Ebihara and Bishop, 1999; Seo and Bishop, 2008). The hypothesis reported in the present work is also in agreement with Raghukumar et al. (2006) who determined that once the PAHs are adsorbed by the biomass they are subsequently metabolized by the microorganisms.

The developed biobarrier of T. longibrachiatum worked in successive batches during more than $70 \mathrm{~d}$ without a significant decrease of its activity. Thus, the present study demonstrates that the biobarrier activity endures along the time. In addition, the ability of Trichoderma species as potential biocontrol agents can be useful in a real application of groundwater treatment where there are no aseptic conditions (Rojo et al., 2007).

\section{Conclusions}

In this work the T. longibraquiatum biofilm over nylon sponge was evaluated for its use as bioreactive material to PRBBs for the treatment of $\mathrm{PAH}$ polluted groundwater. Initially, the capacity of the fungus to grow forming biofilm over nylon sponge was demonstrated. After that, the physiological behavior of bioreactive material focused on PAH removal was tested. The developed material was able to reduce effectively PHE in soil and aqueous medium. Subsequently, the formed reactive material was used in a column reactor to evaluate its performance as PRBB to treat PAH mixtures. The developed fungus biobarrier worked in successive batches during more than $70 \mathrm{~d}$ without a significant decrease of its activity. In view of the achieved results, it can be suggested that the PRBBs of T. longibrachiatum supported on nylon sponge could be a potentially useful method for the treatment of groundwater polluted with PAHs. However, further work is necessary in this field in order to analyze the implementation in a real polluted groundwater.

\section{Acknowledgements}

This research was funded by Spanish Ministry of Science and Innovation and FEDER Funds (Project CTM 2011-25389) and for financial support of Marta Pazos under the Ramón y Cajal programme and Marta Cobas under the final project master grant "Campus do Mar Knowledge in depth".

\section{References}

Bamforth, S.M., Singleton, I., 2005. Bioremediation of polycyclic aromatic hydrocarbons: current knowledge and future directions. J. Chem. Technol. Biotechnol. 80, 723-736

Choi, J., Kim, Y., Choi, S.J., 2007. Reductive dechlorination and biodegradation of 2,4,6-trichlorophenol using sequential permeable reactive barriers: laboratory studies. Chemosphere 67, 1551-1557.

Ebihara, T., Bishop, P.L., 1999. Biofilm structural forms utilized in bioremediation of organic compounds. Water Sci. Technol. 39 (7), 203-210.

EU, 2000. Directive 2000/60/EC of the European parliament and of the council of 23 October, 2000, establishing a framework for community action in the field of water policy. L 327, 72.

Gaanappriya, M., Guhankumar, P., Balakrishnan, V., 2011. Isolation of xylan degrading enzyme from Trichoderma spp. Res. Plant Biol. 1, 15-20.

Gibert, O., Ferguson, A.S., Kalin, R.M., Doherty, R., Dickson, K.W., McGeough, K.L., Robinson, J., Thomas, R., 2007. Performance of a sequential reactive barrier for bioremediation of coal tar contaminated groundwater. Environ. Sci. Technol. 41, 6795-6801.

Harding, M.W., Marques, L.L.R., Howard, R.J., Olson, M.E., 2009. Can filamentous fungi form biofilms? Trends Microbiol. 17, 475-480.

Haritash, A.K., Kaushik, C.P., 2009. Biodegradation aspects of polycyclic aromatic hydrocarbons (PAHs): a review. J. Hazard. Mater. 169, 1-15. 
Inengite, A.K., Oforka, N.C., Osuji-Leo, C., 2012. Sources of polycyclic aromatic hydrocarbons in an environment urbanised by crude oil exploration. Environ. Nat. Resour. Res. 2 (3), 62-70.

Jones, E.B.G., 1994. Fungal adhesion. Mycol. Res. 98, 961-981.

Manoli, E., Samara, C., 1999. Polycyclic aromatic hydrocarbons in natural waters: sources, occurrence and analysis. TrAC Trends Anal. Chem. 18, 417-428.

Moldes, D., Rodríguez Couto, S., Cameselle, C., Sanromàn, M.A., 2003. Study of the degradation of dyes by $\mathrm{MnP}$ of Phanerochaete chrysosporium produced in a fixed-bed bioreactor. Chemosphere 51, 295-303.

Moscoso, F., Teijiz, I., Deive, F.J., Sanromán, M.A., 2012. Efficient PAHs biodegradation by a bacterial consortium at flask and bioreactor scale. Bioresour. Technol. 119, 270-276.

Mueller, J.K., Cerniglia, C.E., Pritchard, P.H., 1998. Bioremediation of environments contaminated by polycyclic aromatic hydrocarbons. In: Crawford, R.L., Crawford, D.L. (Eds.), Bioremediation: Principles and Applications. Cambridge University Press, Cambridge, UK, pp. 125-194.

Pazos, M., Alcántara, M.T., Rosales, E., Sanromán, M.A., 2011. Hybrid technologies for the remediation of diesel fuel polluted soil. Chem. Eng. Technol. 34, 2077-2082.

Raghukumar, C., Shailaja, M.S., Parameswaran, P.S., Singh, S.K., 2006. Removal of polycyclic aromatic hydrocarbons from aqueous media by the marine fungus NIOCC \# 312: involvement of lignin-degrading enzymes and exopolysaccharides. Ind. J. Mar. Sci. 35, 373-379.

Rivera-Cruz, M.D.C., Ferrera-Cerrato, R., Volke-Haller, V., Fernández-Linares, L., Rodríguez-Vázquez, R., 2002. Adaptation and selection of autochthonous microorganisms to culture media with benzo(a)pyrene. Agrocencia 36, 503514.

Rojo, F.G., Reynoso, M.M., Ferez, M., Chulze, S.N., Torres, A.M., 2007. Biological control by Trichoderma species of Fusarium solani causing peanut brown root rot under field conditions. Crop Prot. 26, 549-555.

Rosales, E., Rodríguez Couto, S., Sanromán, A., 2002. New uses of food waste: application to laccase production by Trametes hirsuta. Biotechnol. Lett. 24, 701704

Rosales, E., Pazos, M., Sanromán, M.A., 2012a. Feasibility of solid-state fermentation using spent fungi-substrate in the biodegradation of PAHs. Clean Soil Air Water. http://dx.doi.org/10.1002/clen.201100305.
Rosales, E., Pérez-Paz, A., Vázquez, X., Pazos, M., Sanromán, M.A., 2012b. Isolation of novel benzo[a]anthracene-degrading microorganisms and continuous bioremediation in an expanded-bed bioreactor. Bioprocess Biosyst. Eng. 35, $851-855$.

Sack, U., Heinze, T.M., Deck, J., Cerniglia, C.E., Martens, R., Zadrazil, F., Fritsche, W. 1997. Comparison of phenanthrene and pyrene degradation by different wooddecaying fungi. Appl. Environ. Microbiol. 63, 3919-3925.

Seo, Y., Bishop, P.L., 2008. The monitoring of biofilm formation in a mulch biowall barrier and its effect on performance. Chemosphere 70, 480-488.

Te Biesebeke, R., Ruijter, G., Rahardjo, Y.S.P., Hoogschagen, M.J., Heerikhuisen, M., Levin, A., Van Driel, K.G.A., Schutyser, M.A.I., Dijksterhuis, J., Zhu, Y., Weber, F.J., De Vos, W.M., van Den Hondel, K.A.M.J.J., Rinzema, A., Punt, P.J., 2002. Aspergillus oryzae in solid-state and submerged fermentations: progress report on a multidisciplinary project. FEMS Yeast Res. 2, 245-248.

Thiruvenkatachari, R., Vigneswaran, S., Naidu, R., 2008. Permeable reactive barrier for groundwater remediation. J. Ind. Eng. Chem. 14, 145-156.

Tiehm, A., Müller, A., Alt, S., Jacob, H., Schad, H., Weingran, C., Tiehm, A., Müller, A. Alt, S., Jacob, H., Schad, H., Weingran, C., 2008. Development of a groundwater biobarrier for the removal of polycyclic aromatic hydrocarbons, BTEX, and heterocyclic hydrocarbons. Water Sci. Technol. 58, 1349-1355.

Tredoux, G., Cavé, L., Engelbrecht, P., 2004. Groundwater pollution: are we monitoring appropriate parameters? Water SA 30, 662-667.

Villena, G.K., Gutierrez-Correa, M., 2003a. Biopelículas de Aspergillus niger para la producción de celulasas: algunos aspectos estructurales y fisiológicos. Rev. Peru. Biol. 10, 78-87.

Villena, G.K., Gutierrez-Correa, M., 2003b. Fermentación por adhesión a superficies: una nueva categoría fermentativa. Rev. Peru. Biol. 10, 113-124.

Warner, S.D., 2011. Permeable reactive barriers. Radwaste Sol. 18, 30-34.

Yerushalmi, L., Manuel, M.F., Guiot, S.R., 1999. Biodegradation of gasoline and BTEX in a microaerophilic biobarrier. Biodegradation 10, 341-352.

Zein, M.M., Pinto, P.X., Garcia-Blanco, S., Suidan, M.T., Venosa, A.D., 2006. Treatment of groundwater contaminated with PAHs, gasoline hydrocarbons, and methyl tert-butyl ether in a laboratory biomass-retaining bioreactor. Biodegradation 17, 57-69. 